(21.5\%), smoking [current 83(28.3\%); ex 103(35.2\%)], hypertension 155(52.5\%), hyperlipidaemia 207(70.6\%), or diabetes 67(22.3\%). Past CV history included prior MI 57(19.4\%), prior revascularisation 53(18.1\%), TIA/stroke 22(7.5\%) or peripheral arterial disease 33(11.3\%). Lipid levels pre or within 24 hours of admission were available in 248(84\%) patients. For those already on lipid treatment 144 (49.1\%) and an admission LDL was available, mean LDL-C was $2.15 \mathrm{mmol} / 1$; for those not on treatment, mean LDL-C was $3.27 \mathrm{mmol} / \mathrm{l}$. At discharge, 269(91.8\%) patients were receiving lipid lowering therapy [atorvastatin 242 (90\%); rosuvastatin $15(5.6 \%)$; simvastatin $8(2.97 \%)$; pravastatin $2(0.01 \%)$; and 1 person on ezetimibe]. Follow up lipids at $>3$ months were available in $166(56.7 \%)$ in whom mean LDL-C was $1.87 \mathrm{mmol} / \mathrm{l}$ and $82(49.4 \%)$ met the ESC target of $<1.8 \mathrm{mmol} /$ 1. For those not at target, adjustment in lipid treatment was undertaken in 11(10\%) [statin increase/switch in all cases]. Follow up lipids beyond 6 months were obtained in 190 (64.8\% of lipids) of those $110(57 \%)$ achieved and LDL-C of $<1.8 \mathrm{mmol} / \mathrm{L} ; 15(7.8 \%)$ had LDL-C of $3 \mathrm{mmol} / \mathrm{L}$.

Conclusion In an unselected consecutive acute MI population, despite use of contemporary intensive statin therapy in $>90 \%$ of patients, LDL-C levels remain suboptimal in 92(27\%) of those taking statins. Lipid follow up is a key element of follow up with need for adjustment in statin \pm additional treatment required in approximately $30 \%$ of patients.

\section{META-ANALYSIS OF RANDOMISED CONTROLLED TRIALS INVESTIGATING THE IMPACT OF COLCHICINE ON MAJOR ADVERSE CARDIOVASCULAR EVENTS IN ACUTE CORONARY SYNDROME}

${ }^{1} \mathrm{~N}$ Blake, ${ }^{1} \mathrm{~A}$ Alonso, ${ }^{1,2} \mathrm{H}$ Rai, ${ }^{1,2} \mathrm{R}$ Colleran, ${ }^{1,2} \mathrm{D}$ Giacoppo, ${ }^{1,2} \mathrm{G}$ Blake, ${ }^{1,2} \mathrm{RA}$ Byrne. ${ }^{1}$ Mater Private Hospital, Cardiovascular Research Institute (CVRI) Dublin, Ireland; ${ }^{2} R C S I$ School of Pharmacy and Biomolecular Sciences, Royal College of Surgeons, Dublin, Ireland

10.1136/heartjnl-2021-ICS.47

Introduction Colchicine has been shown to reduce inflammation and has a potential to stabilise atherosclerotic plaques. Clinical studies have suggested a role for colchicine in reducing adverse cardiovascular events in patients with coronary artery disease. The aim of the present meta-analysis was to investigate the effect of colchicine on outcomes following coronary intervention among patients presenting with acute coronary syndrome (ACS).

Methods We searched for randomised controlled trials (RCTs) comparing colchicine to placebo in patients with ACS undergoing coronary intervention using the initial MESH terms 'colchicine' and 'cardiovascular system'. Eligible RCTs published up to November 2020 were included. We also searched presentations from the proceedings of relevant international scientific meetings. The primary endpoint was major adverse cardiovascular events (MACE). Study level odds ratios (ORs) and $95 \%$ confidence intervals (CI) of MACE were pooled using the Mantel-Haenszel method and random effects model. Forest plots were generated using Review Manager (RevMan) 5.4 software.

Results Our initial search identified 1,049 articles for potential inclusion. Of these studies, 4 RCTs were found to be eligible: COPS, COLCHICINE-PCI, COLCOT time-to-Initiation (TTI) 0-3 days and PODCAST-PCI. Overall a total of 2,709 patients were randomly allocated to treatment with either colchicine $(n=1,367)$ or placebo $(n=1,342)$. Patients received colchicine either prior to angiography or within 3 days post-procedure. Follow up duration ranged from 30 days to 3 years. Mean age of the whole analysed cohort was $60.3 \pm 10.5$ years; $73 \%$ were male; $51 \%$ had a history of hypertension, $26 \%$ had diabetes mellitus, 38\% were current smokers. There were 89 events in the colchicine group as opposed to 133 events in the placebo group. The risk of MACE was lower in patients treated with colchicine as compared with placebo (OR 0.63, $95 \%$ CI $0.48-0.84, \mathrm{p}=0.001$ ) (see figure 1). Heterogeneity across trials was not detectable $\left(\mathrm{I}^{2}=0\right)$.

Conclusions The results of our meta-analysis suggest that among patients presenting with acute coronary syndrome undergoing coronary intervention, treatment with colchicine instead of placebo reduces the risk of MACE. Further investigations in larger cohorts are warranted to test this effect.

\section{8 IDENTIFICATION OF NOVEL PROTEIN BIOMARKERS FOR ATRIAL FIBRILLATION}

${ }^{1} \mathrm{C}$ Tonry, ${ }^{1} \mathrm{~A}$ Russell-Hallinan, ${ }^{2} \mathrm{P}$ Collier, ${ }^{3,4} \mathrm{~K}$ McDonald, ${ }^{3,4} \mathrm{M}$ Ledwidge, ${ }^{5} \mathrm{~B}$ Collins, ${ }^{1,3,4} \mathrm{CJ}$ Watson. ${ }^{1}$ Wellcome-Wolfoson Institute of Experimental Medicine, Queens University Belfast, UK; ${ }^{2}$ Department of Cardiovascular Medicine, Cleveland Clinic, OH; ${ }^{3}$ STOP-HF Unit, St. Vincent's University Healthcare Group, Dublin, Ireland; ${ }^{4}$ Heartbeat Trust, Dublin, Ireland; ${ }^{5}$ School of Biological Sciences, Queens University Belfast

10.1136/heartjnl-2021-ICS.48

NOT AVAILABLE FOR PUBLICATION

\section{DYSLIPIDAEMIA MANAGEMENT IN THE CARDIAC REHABILITATION CLINIC OF A TERTIARY REFERRAL CENTRE; ANALYSIS OF THE IMPACT OF NEW ESC GUIDANCE ON LDL-C TARGET ACHIEVEMENT}

C McCaughey, D Ranganathan, M Kerins, G Murphy, R Murphy. St James's Hospital Dublin, Ireland

\subsection{6/heartjnl-2021-ICS.49}

Background Cardiac rehabilitation (CR) programs provide an opportunity to measure low density lipoprotein cholesterol (LDL-C) levels and optimise lipid lowering therapy (LLT) accordingly. New ESC guidelines released in August 2019

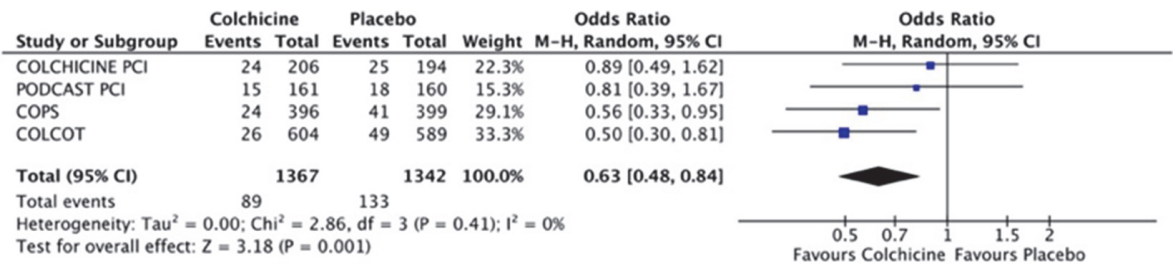

Abstract 47 Figure 1 Risk of MACE in patients treated with colchicine as compared with placebo 
recommend lower absolute LDL-C target levels and an $>50 \%$ reduction from baseline in those at the highest risk.

Purpose This study investigated the proportion of those patients who finished CR in 2019 that reached both their absolute and relative reduction in LDL-C levels, before and after the introduction of these new guidelines. We also analysed the choice and appropriateness of LLT.

Methods A retrospective chart review of 163 patients who completed CR in 2019 [table 1]. A database was created containing baseline patient characteristics and LDL-C levels both prior and post CR; as well as the patient's contemporary LLT. Those patients who did not have a previous diagnosis of atherosclerotic cardiovascular disease (ASCVD) were risk stratified as per ESC guidance. Baseline LDL-C levels were recorded, where possible, and otherwise calculated using pre-CR LDL profile with an adjustment made based on the projected effects of their LLT.

Results Mean (SD) patient age was 62 (10) years, 123/163 $(75 \%)$ were male and $142(87 \%)$ patients had established ASCVD. 90/142 (63\%) of very high-risk patients were on a high intensity LLT and 5/163 overall (3\%) were prescribed Ezetimibe. Overall, 96/163 (59\%) patients in 2019 met their absolute LDL-C targets; $62 \%$ of applicable patients achieved an $>50 \%$ reduction in LDL-C levels. 104 (64\%) of patients were treated in compliance with their contemporary guidelines. Both pre $(n=112)$ and post $(n=51)$ September 2019 cohorts were well matched. Fewer patients who were treated under the August 2019 guidelines reached their absolute LDLC $(51 \%$ v $63 \%, \mathrm{p}<0.005)$ targets; achieved a $>50 \%$ reduction in LDL-C from baseline $(48 \%$ vs $61 \%, \mathrm{p}<0.005)$, or

Abstract 49 Table 1 Baseline characteristics of patients who completed CR in 2019

\begin{tabular}{|c|c|c|c|c|}
\hline Guidelines & 2016 & 2019 & Total & $p$ \\
\hline \multicolumn{5}{|l|}{ Age } \\
\hline Mean (*SD) & $63(9) a$ & $61(11) a$ & $62(10) a$ & $0.234 b$ \\
\hline \multicolumn{5}{|l|}{ Sex } \\
\hline Female & $26(23)$ & $14(28)$ & $40(25)$ & 0.56 \\
\hline Male & $86(77)$ & $37(73)$ & $123(76)$ & \\
\hline \multicolumn{5}{|l|}{ Prevention Strategy } \\
\hline Primary Prevention & $13(12)$ & $8(16)$ & $21(13)$ & \\
\hline Secondary Prevention & $99(88)$ & $43(84)$ & $142(87)$ & 0.52 \\
\hline \multicolumn{5}{|l|}{ Risk Category } \\
\hline Very High & $99(88)$ & $43(84)$ & $142(87)$ & 0.491 \\
\hline High & $3(3)$ & $2(4)$ & $5(3)$ & \\
\hline Moderate & $11(10)$ & $5(10)$ & $16(10)$ & \\
\hline Low & $0(0)$ & $1(2)$ & $1(1)$ & \\
\hline \multicolumn{5}{|l|}{ Lipid Lowering Therapy } \\
\hline No Lipid Lowering Therapy & $21(19)$ & $22(43)$ & $43(26)$ & $<0.005$ \\
\hline Low Monotherapy & $3(3)$ & $1(2)$ & $4(2)$ & \\
\hline Moderate Monotherapy & $33(29)$ & $8(16)$ & $41(25)$ & \\
\hline High Monotherapy & $62(55)$ & $29(56)$ & $91(56)$ & \\
\hline Moderate + Ezetimibe & $2(2)$ & $0(0)$ & $2(1)$ & \\
\hline High+ Ezetimibe & $2(2)$ & $0(0)$ & $2(1)$ & \\
\hline Unknown & $0(0)$ & $8(16)$ & $8(5)$ & \\
\hline Ezetimibe Monotherapy & $0(0)$ & $1(2)$ & $1(1)$ & \\
\hline None & $10(9)$ & $4(48$ & $14(9)$ & \\
\hline \multicolumn{5}{|l|}{ Family History } \\
\hline Yes & $78(70)$ & $15(29)$ & $93(57)$ & \\
\hline None & $42(38)$ & $12(24)$ & $54(33)$ & \\
\hline Missing & $4(4)$ & $27(53)$ & 31 (19) & \\
\hline \multicolumn{5}{|l|}{ Smoking Status } \\
\hline Current & $3(3)$ & $0(0)$ & $3(2)$ & \\
\hline Ex<6months & $22(20)$ & $2(4)$ & $24(15)$ & \\
\hline Ex>6months & $16(14)$ & $1(2)$ & $17(10)$ & \\
\hline Ex $>5 y r s$ & $24(21)$ & $8(16)$ & $32(20)$ & \\
\hline Missing & $5(5)$ & $28(55)$ & $33(20)$ & \\
\hline Never & $23(21)$ & $5(10)$ & $28(17)$ & \\
\hline \multicolumn{5}{|l|}{ Dyslipidaemia } \\
\hline Yes & $81(72)$ & $16(31)$ & $97(60)$ & \\
\hline No & $95(85)$ & $20(39)$ & $115(71)$ & \\
\hline
\end{tabular}


Abstract 49 Table 2 Summary of LDL-C values for those patients who completed CR in 2019, stratified by treatment guidline and risk category Table 3: Table displaying the LDL-C level attainment for those patients who completed CR in 2019, stratified by guidelines used. The number of patients for whom LDL-C data prior to commencement to commencing CR is given, with percentage of row total in brackets. The mean measured LDL-C level prior and following completion of cardiac rehab is given with $95 \%$ confidence intervals for the mean in brackets. The number of patients who met their absolute LDL-C category for their specified risk category is displayed with row percentage displayed in brackets. The percentage at reduction of LDL-C from measured or calculated baseline LDL-C is given, with $95 \%$ confidence intervals for the mean displayed in brackets. The number of patients who achieved an over 50\% reduction in their LDL-C level when compared to their measured or calculated baseline LDL-C level is given with row percentage in brackets, The number of patients who met their LDL-C guidelines as defined by their contemporary guidelines is displayed with row percentage in brackets. For the 2016 cohort, this required achievement of a reduction of LDL-C below an absolute target, and for those at very high and high risk, a relative reduction of at least $50 \%$ LDL-C when compared to measured or calculated baseline lipids. For the 2019 cohort, both of these criteria must be satisfied.

\begin{tabular}{|c|c|c|c|c|c|c|c|c|}
\hline $\begin{array}{l}\text { Risk } \\
\text { Category }\end{array}$ & $\mathrm{N}$ & $\begin{array}{l}\text { Baseline } \\
\text { LDL-C } \\
\text { Available }\end{array}$ & $\begin{array}{l}\text { LDL-C Pre- } \\
\text { CR }\end{array}$ & $\begin{array}{l}\text { LDL-C Post- } \\
\text { CR }\end{array}$ & $\begin{array}{l}\text { Absolute } \\
\text { LDL-C } \\
\text { Target Met }\end{array}$ & $\begin{array}{l}\text { \% LDL-C } \\
\text { Red. from } \\
\text { baseline }\end{array}$ & $\begin{array}{l}>50 \% \\
\text { Red. LDL- } \\
\text { C }\end{array}$ & $\begin{array}{l}\text { Guideliı } \\
\text { Achiev€ }\end{array}$ \\
\hline \multicolumn{9}{|l|}{$\begin{array}{l}2016 \\
\text { Guidelines }\end{array}$} \\
\hline Very High & 99 & $76(77)$ & $\begin{array}{l}2.72(2.48- \\
2.97)\end{array}$ & $\begin{array}{l}1.67(1.52- \\
1.82)\end{array}$ & $61(62)$ & $61(56-66)$ & $49(70)$ & $73(73)$ \\
\hline High & 2 & $1(50)$ & $4.03\left(\mathrm{NA}^{*}\right)$ & $4.5\left(\mathrm{NA}^{*}\right)$ & $1(50)$ & 70 (NA*) & $1(100)$ & $1(50)$ \\
\hline Moderate & 11 & & $\begin{array}{l}2.69(1.33- \\
4.05)\end{array}$ & $\begin{array}{l}0.95((-0.9)- \\
2.82)\end{array}$ & $8(73)$ & & & $8(72)$ \\
\hline Low & 0 & & & & & & & \\
\hline Subtotal & 112 & $81(72)$ & $\begin{array}{l}2.70(2.46- \\
2.93)\end{array}$ & $\begin{array}{l}1.64(1.49- \\
1.79)\end{array}$ & $70(63)$ & $61(56-66)$ & $50(65)$ & $82(73)$ \\
\hline \multicolumn{9}{|c|}{2019 Guidelines } \\
\hline Very High & 43 & $30(70)$ & $\begin{array}{l}3.34(3.01- \\
3.66)\end{array}$ & $\begin{array}{l}2.86(2.39- \\
3.34)\end{array}$ & $21(49)$ & $50(40-61)$ & $11(37)$ & $18(42)$ \\
\hline High & 2 & $2(100)$ & 2.91 (NA*) & 4.81 (NA*) & $1(50)$ & $\begin{array}{l}13.92 \\
\left(\mathrm{NA}^{*}\right)\end{array}$ & $0(0)$ & $0(0)$ \\
\hline Moderate & 5 & & $\begin{array}{l}3.45(1.56- \\
5.34)\end{array}$ & $\begin{array}{l}2.25(1.01- \\
3.48)\end{array}$ & $3(60)$ & & & $3(60)$ \\
\hline Low & 1 & & & & $1(100)$ & & & $1(100)$ \\
\hline Subtotal & 51 & $37(73)$ & $\begin{array}{l}2.83(2.41- \\
3.25)\end{array}$ & $\begin{array}{l}1.83(1.41- \\
2.25)\end{array}$ & $26(51)$ & $48(37-59)$ & $11(34)$ & $22(43)$ \\
\hline \multicolumn{9}{|l|}{ All Patients } \\
\hline Very High & 142 & $108(76)$ & $\begin{array}{l}2.68(2.48- \\
2.88)\end{array}$ & $\begin{array}{l}1.60(1.47- \\
1.72)\end{array}$ & $82(58)$ & $58(53-63)$ & $68(67)$ & $91(64)$ \\
\hline High & 4 & $3(75)$ & $\begin{array}{l}3.28 \text { (1.56- } \\
5.00)\end{array}$ & $\begin{array}{l}2.43(1.02- \\
3.84)\end{array}$ & $2(50)$ & $32\left(N^{*}\right)$ & $1(33)$ & $1(25)$ \\
\hline Moderate & 16 & & $\begin{array}{l}3.02(2.23- \\
3.80)\end{array}$ & $\begin{array}{l}2.43(1.91- \\
2.94)\end{array}$ & $11(69)$ & & & $11(69)$ \\
\hline Low & 1 & & & & $1(100)$ & & & $1(100)$ \\
\hline Total & 163 & $118(72)$ & $\begin{array}{l}2.72(2.52- \\
2.91)\end{array}$ & $\begin{array}{l}1.69(1.57- \\
1.82)\end{array}$ & 96 (59) & $57(52-62)$ & $61(52)$ & $104(64$ \\
\hline
\end{tabular}

'Baseline lipids do not refer to 'LDL-C pre-rehab' column, but instead the measured LDL-C level for those not on LLT (or the calculated LDL-C level of a patient. adjusted for LLT effect), prior to commencing CR.CR- Cardiac Rehabilitation

were compliant with the guidelines for their risk category (43\% vs $73 \%, \mathrm{p}<0.005)$.

Conclusions Both high intensity statin therapy and ezetimibe are under-prescribed. Fewer patients are meeting the lower absolute LDL-C targets set out in the 2019 ESC guidelines. For those at high risk, determining the reduction in LDL-C from baseline reveals even those meeting their absolute LDL-C targets may still be undertreated.

\section{WHICH LIFESTYLE BEHAVIOURS SHOULD WE BE FOCUSING ON AND HOW DO THEY RELATE TO BNP IN PRE-CLINICAL HEART FAILURE?}

1,2,3B Wong, ${ }^{2} \mathrm{~A}$ McDermot, ${ }^{3} \mathrm{P}$ Creechan, ${ }^{1} \mathrm{~A}$ Radhakrishna, ${ }^{2} \mathrm{~S}$ Muhamme, ${ }^{1} \mathrm{~A}$ Brennan, ${ }^{2} \mathrm{~A}$ Moore, ${ }^{1,2,3} \mathrm{M}$ Ledwidge, ${ }^{1,2,3} \mathrm{~K}$ McDonald. 'St Vincent's University Hospital, Dublin, Ireland; ${ }^{2}$ Heartbeat Trust, Dublin, Ireland; ${ }^{3}$ University College Dublin School of Medicine, Dublin, Ireland

10.1136/heartjnl-2021-ICS.50

Background Heart failure (HF) prevention is a central component in our strategy against the growth in prevalence of this syndrome. This strategy comprises the use of specific therapies such as Renin-Angiotensin-Aldosterone System modifying therapies and more recently Sodium GLucose Transporter-2 inhibitors, but also relies on adoption of good cardiovascular (CV) lifestyle measures. These are encapsulated by Life's Simple 7 (LS7). LS7 include: not smoking, a healthy BMI,

Simple Bar Count of Total Life's Simple 7 Score

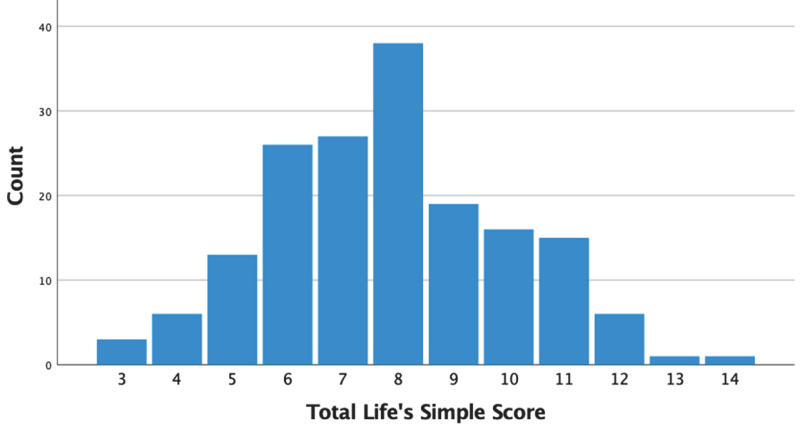

Abstract 50 Figure 1 Composite of life's simple 7 frequency 